\title{
A Study on Expansion Process of a Cold Storage Using Taguchi L9 Orthogonal Analysis
}

\author{
Dr. Nimai Mukhopadhyay ${ }^{1}$, Bidhan Chandra Das $^{2}$ \\ ${ }^{1}$ (Assistant Professor, Department of Mechanical Engineering, Jalpaiguri Government Engineering College, \\ Jalpaiguri-735102, WB, India \\ ${ }^{2}$ (Post Graduate Scholar, Department of Mechanical Engineering, Jalpaiguri Government Engineering College, \\ Jalpaiguri-735102, WB, India
}

\begin{abstract}
This paper is concerned with the overview of project based on the theoretical study and analysis of expansion process of a cold storage using Taguchi analysis. The objective of this study is to illustrate how change in entropy $(\Delta S)$ in expansion process is effected by several parameters or control factors of refrigeration system in a cold storage. In this paper, we have proposed a mathematical model of change in entropy $(\Delta S)$ in expansion process of a cold storage using Taguchi L9 \& L18 orthogonal array. Inlet temperature (T1) \& Outlet temperature (T2) of expansion process and pressure ratio (Pr) of expansion process are the basic variables with their three ranges and each of them are taken in the mathematical model development.

Keywords: Taguchi L9, Expansion process, Cold Storage, Change in Entropy $(\Delta S)$
\end{abstract}

\section{INTRODUCTION}

Cold storage is generally used for preserving food commodities and preventing them from perishing so that foods can be supplied uniformly throughout the year. India is having variety of season and wide range of soil thus producing variety of fruit and vegetables likegrapes, apples, potatoes, chilies, ginger, garlic etc. While preserving those fruits \& vegetables, it is very necessary to maintain a particular temperature \& environment condition to keep it fresh \& usable and cold storage is the prime infrastructural component for such commodities. Besides the role of stabilizing market prices and evenly distributing both on demand basis and time basis, the cold storage industry provide other advantages and benefits to both the farmers and the consumers. A little theoretical and experimental study is being reported in the journal on the performance enhancement of cold storage.

Now-a-days, energy crisis has become a headache worldwide. Cold storage is required huge amount of electrical energy to operate the refrigeration system and as the demand of cold storage is increasing rapidly, so consumption of electrical energy is also increased. It is very important to make cold storage energy efficient or in the other words reduce its energy consumption.

\footnotetext{
In Vapour Compression Refrigeration system, high pressure, high temperature refrigerants leaving the condenser is cooled and reduced pressure through expansion process. Expansion process is an isenthalpic process i.e. there is no heat transfer $(\Delta \mathrm{h}=0)$ during this process.
}

In this project we have proposed a mathematical model of change in entropy $(\Delta S)$ of expansion process with three control factors $(\mathrm{T} 1=$ Inlet temperature of expansion process, $\mathrm{T} 2=$ Outlet temperature of expansion process, $\mathrm{Pr}=$ Pressure ratio of expansion process) by using Taguchi methods and graphical interpretations from the model justify the reality.

\section{MODEL DEVELOPMENT}

Entropy of an ideal gas during expansion process of vapor compression refrigeration system is given by; $\Delta S=C_{p} \log \left(\frac{\mathrm{T} 2}{\mathrm{~T} 1}\right)-R_{c} \log (\mathrm{Pr})$

Where, $\Delta \mathrm{S}=$ Change in entropy $(\mathrm{KJ} / \mathrm{Kg}-\mathrm{K}) ; C_{p}=$ Specific heat at constant pressure $(\mathrm{KJ} / \mathrm{Kg}-\mathrm{K})$; $\mathrm{T} 1=$ Inlet temperature of expansion process $(\mathrm{K}) ; \mathrm{T} 2=$ Outlet temperature of expansion process $(\mathrm{K}) ; R_{c}=$ Characteristic gas constant $(\mathrm{KJ} / \mathrm{Kg}-\mathrm{K})=(\mathrm{R} / \mathrm{n})$ where, $\mathrm{R}=$ universal gas constant $(\mathrm{KJ} / \mathrm{mol}-\mathrm{K}), \mathrm{n}=$ Molar mass $(\mathrm{Kg} / \mathrm{mol})$; $\operatorname{Pr}=$ Pressure ratio of expansion process $(\mathrm{P} 2 / \mathrm{P} 1)$.

With the help of Taguchi methodology we constructed our design matrix of experiments in which change in entropy $(\Delta S)$ is the response variable. The predictor variables are Inlet temperature of expansion process (T1), Outlet temperature of expansion process (T2) and Pressure ratio of expansion process (Pr).

Orthogonal arrays are used to obtain a well balanced minimum set of experiments. It was developed by C.R.Rao and popularized by Genechi Taguchi .We used full set design matrix of L9 orthogonal array and one row of L18 orthogonal array to create the mathematical model. 


\section{REGRESSION ANALYSIS}

Regression analysis is a statistical tool which provides us relationship between response and predictor variables. By regression analysis we can tell how response variable changes with change of the predictor variables. Simple regression equation is $\mathrm{Y}=\mathrm{a}+\mathrm{bX}$. As we have to consider more than one predictor variable, so simple regression analysis cannot be used. In this problem multiple regression analysis was adopted to obtain the mathematical model. There are two types of mu ltiple regression analys is -

1. Simple Multiple regression analysis (First order) i.e. -

$\mathrm{Y}=\beta_{0}+\beta_{1} X_{1}+\beta_{2} X_{2}+\beta_{3} X_{3} \ldots \ldots \ldots \ldots \ldots+\varepsilon$, where $\mathrm{Y}$ is the response variable, $\mathrm{X}$ is the predictor variables, $\beta$ is the coefficients and $\varepsilon$ is the experimental error.

2. Polynomial multiple regression analysis (Second order or more )i.e.-

$$
\mathrm{Y}=\beta_{0}+\beta_{1} \mathrm{X} 1+\beta_{2} \mathrm{X} 2+\beta_{3} \mathrm{X} 3+
$$
$\beta 4 \mathrm{X} 1 * \mathrm{X} 1+\beta 5 \mathrm{X} 2 * \mathrm{X} 2+\beta 6 \mathrm{X} 3 *$

$\mathrm{X} 3+\beta 7 \mathrm{X} 1 * \mathrm{X} 2+\beta 8 \mathrm{X} 2 * \mathrm{X} 3+\quad \beta 9(\mathrm{X} 3 * \mathrm{X} 1)$

This equation is second order polynomial equation with three variables i.e. $\mathrm{X} 1, \mathrm{X} 2, \mathrm{X} 3$; Y is the response variable and $\beta$ is the coefficients. In this project we used this equation to form the mathematical model. When $\Delta S=$ Response variable; Inlet temperature (T1), Outlet temperature (T2) \& $\operatorname{Pr}=$ Pressure ratio of expansion process are control factors, final equation looks like -

$\Delta \mathrm{S}=\beta_{0}+\beta_{1} \mathrm{~T} 1+\beta_{2} \mathrm{~T} 2+\beta_{3} \mathrm{Pr}+\beta_{4}(\mathrm{~T} 1 * \mathrm{~T} 1)+$ $\beta_{5}(\mathrm{~T} 2 * \mathrm{~T} 2)+\beta_{6}(\mathrm{Pr} * \mathrm{Pr})+\beta_{7}(\mathrm{~T} 1 * \mathrm{~T} 2)+\beta_{8}(\mathrm{~T} 2 * \mathrm{Pr})$ $+\beta_{9}\left(\mathrm{Pr}^{*} \mathrm{~T} 1\right)$

This equation can be solved by following matrix method $-[\beta]=[\mathrm{Y}]^{*}[\mathrm{X}]^{-1}$, Where, $[\beta]=$ Coefficients matrix; $[\mathrm{Y}]=$ Response variable matrix; $[\mathrm{X}]^{-1}=$ inverse of control variables matrix;

In this problem there are three variables with three different range or level, so Taguchi Orthogonal Array (OA) L9 design matrix table is used to do the theoretical experiment. But L9 Orthogonal table gives us nine equation and no of unknown coefficients are ten (i.e. - $[\mathrm{X}]=\left[10^{*} 9\right]$ ). It is not possible to solve these sets of equation in above said matrix method. To solve this problem we did one extra experiment which we took from L18 Orthogonal array. Now we can easily solve this equation in the above said matrix method because no of equation is equal to no of unknown coefficient (i.e. $[\mathrm{X}]=[10 * 10])$.

\section{CONTROL FACTORS \& RANGES}

Table-1: Three control factors and their range or level are shown in below table -

\begin{tabular}{|l|l|l|l|}
\hline CONTROL & LEVEL & MIGH(3) \\
\cline { 2 - 4 } & LOW(1) & MEDIUM(2) & HIORS \\
\hline $\begin{array}{l}\text { Inlet } \\
\text { Temperature(T1) } \\
\text { in (K) }\end{array}$ & 301 & 303 & 305 \\
\hline $\begin{array}{l}\text { Outlet } \\
\text { Temperature(T2) } \\
\text { in (K) }\end{array}$ & 255 & 257 & 259 \\
\hline Pressure Ratio(Pr) & 0.18 & 0.19 & 0.20 \\
\hline
\end{tabular}

\section{THEORETICAL EXPERIMENT}

Taguchi L9 Orthogonal array and one row of L18 Orthogonal array were used.

Table-2: L9 Orthogonal Array (OA) co mbination table-

\begin{tabular}{|l|l|l|l|}
\hline \multirow{2}{*}{$\begin{array}{l}\text { EXPERIMENT } \\
\text { NO. }\end{array}$} & \multicolumn{4}{|l|}{ CONTROL FACTORS } \\
\cline { 2 - 4 } & $\mathrm{A}$ & $\mathrm{B}$ & $\mathrm{C}$ \\
\hline 1 & 1 & 1 & 1 \\
\hline 2 & 1 & 2 & 2 \\
\hline 3 & 1 & 3 & 3 \\
\hline 4 & 2 & 1 & 2 \\
\hline 5 & 2 & 2 & 3 \\
\hline 6 & 2 & 3 & 1 \\
\hline 7 & 3 & 1 & 3 \\
\hline 8 & 3 & 2 & 1 \\
\hline 9 & 3 & 3 & 2 \\
\hline
\end{tabular}


We used L9 orthogonal array table and only one row from L18 Orthogonal array table (i.e. - Experiment no (row no).-14) for theoretical experiment and we got following result table-

Table-3: Theoretical Analysis Table-

\begin{tabular}{|c|c|c|c|c|}
\hline \multirow{2}{*}{$\begin{array}{l}\text { EXP. } \\
\text { NO }\end{array}$} & \multicolumn{3}{|c|}{ CONTROL FACTORS } & \multirow{2}{*}{$\begin{array}{l}\text { RESPONSE } \\
(\Delta \mathrm{S}) \\
(\mathrm{KJ} / \mathrm{Kg}-\mathrm{K}) \\
\end{array}$} \\
\hline & $\begin{array}{l}\text { Inlet Temp.(T1) } \\
(\mathrm{K})\end{array}$ & $\begin{array}{l}\text { Outlet } \\
\text { Temp.(T2) (K) }\end{array}$ & $\begin{array}{l}\text { Pressure } \\
\text { Ratio(Pr) }\end{array}$ & \\
\hline 1 & 301 & 255 & 0.18 & 0.21549 \\
\hline 2 & 301 & 257 & 0.19 & 0.21100 \\
\hline 3 & 301 & 259 & 0.20 & 0.20705 \\
\hline 4 & 303 & 255 & 0.19 & 0.19811 \\
\hline 5 & 303 & 257 & 0.20 & 0.19421 \\
\hline 6 & 303 & 259 & 0.18 & 0.22347 \\
\hline 7 & 305 & 255 & 0.20 & 0.18136 \\
\hline 8 & 305 & 257 & 0.18 & 0.21068 \\
\hline 9 & 305 & 259 & 0.19 & 0.20614 \\
\hline 10 & 305 & 255 & 0.19 & 0.19224 \\
\hline
\end{tabular}

In this study, values of control parameters or factors(T1,T2,Pr) were taken from SRIRAM COLD STORAGE, Jalpaiguri, West Bengal735102 and corresponding $\Delta S$ was calculated from the equation - $\quad \Delta \mathrm{S}=C_{\boldsymbol{p}} \log \left(\frac{\mathrm{T} 2}{\mathrm{~T} 1}\right)-$

$\boldsymbol{R} \boldsymbol{c l o g} \mathbf{P r}$ where, $\boldsymbol{R} \boldsymbol{c}=$ characteristic gas constant of Ammonia $=0.4882 \mathrm{KJ} / \mathrm{Kg}-\mathrm{K} \quad \& \boldsymbol{C}_{\boldsymbol{p}}=$ Specific heat at constant pressure of Ammonia $=2.056 \mathrm{KJ} / \mathrm{Kg}-\mathrm{K}$. Nine theoretical experiments were done according to the L9 Orthogonal array and one experiment was done according to L18 Orthogonal array. Then solved these ten sets of equation in MATLAB by matrix method and got the required values of coefficient. The proposed mathematical model from theoretical experiment -

$\Delta \mathrm{S}=-\mathbf{7 6 . 5 4 5 5}+0.4310 * \mathrm{~T} 1+0.1552 * \mathrm{~T} 2-$ $89.7189 * \operatorname{Pr}-0.0006(\mathrm{~T} 1 * \mathrm{~T} 1)-0.0000(\mathrm{~T} 2 * \mathrm{~T} 2)-$

\subsection{9(Pr*Pr) - $0.0006(T 1 * T 2) \quad+$ $0.1113(\mathrm{~T} 2 * \mathrm{Pr})+0.2222(\operatorname{Pr} * \mathrm{~T} 1)$}

\section{RESULT \& ANALYSIS}

Above regression equation was simulated in computer to find out the effect of control factors $(\mathrm{T} 1, \mathrm{~T} 2, \mathrm{Pr})$ on change in entropy $(\Delta \mathrm{S})$ in expansion process of a cold storage within the considered range or levels. This is done by using a computer C-Programming which gives the responses for each input and it's done by varying one parameter at a time within the considered range while keeping other two parameters constant at a particular value.

6.1 Effect of Inlet temperature (T1) of expansion process on Change in entropy $(\Delta \mathrm{S})$ -

Fig.-1 variation of Change of entropy $(\Delta S)$ with In let temperature (T1)

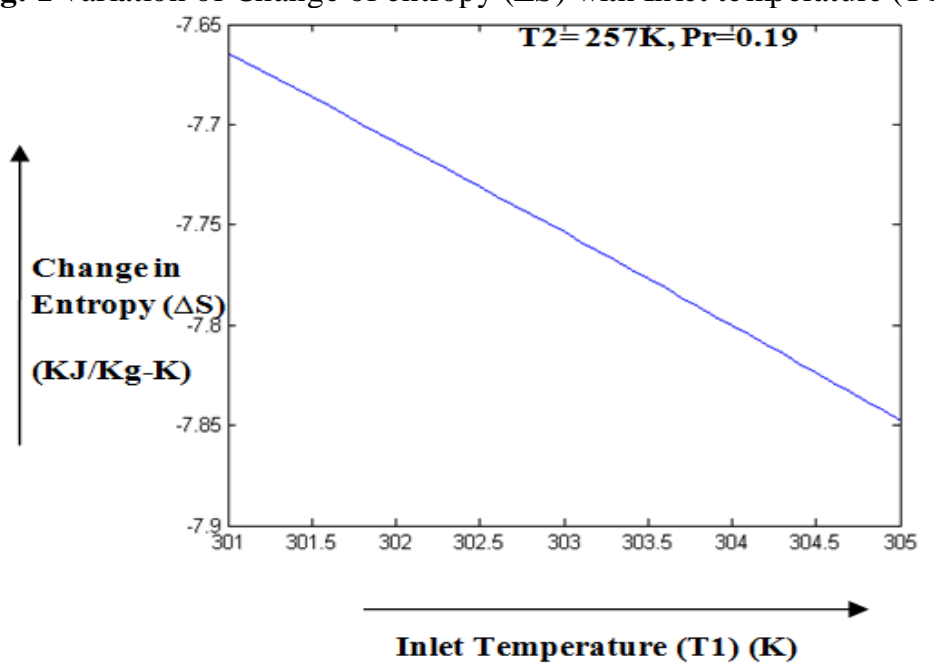

Fig.-1 shows the variation of change in entropy $(\Delta S)$ with the change of inlet temperature (T1). Inlet Temperature is made to vary from $303 \mathrm{~K}$ to
$305 \mathrm{~K}$ and Outlet temperature (T2) \& Pressure ratio (Pr) are kept constant at $257 \mathrm{~K} \& 0.19$ respectively. From the figure it is clear that change in entropy 
decreases with increase of inlet temperature. We know that from second law of thermodynamics, 6.2 Effect of Outlet temperature (T2) of expansion process on Change in entropy $(\Delta S)$ -
$\Delta \mathrm{S}=\Delta \mathrm{Q} / \mathrm{T}$ as temperature increases the change in entropy decreases.

Fig-2 Variation of change in entropy $(\Delta S)$ with Outlet temperature (T2)

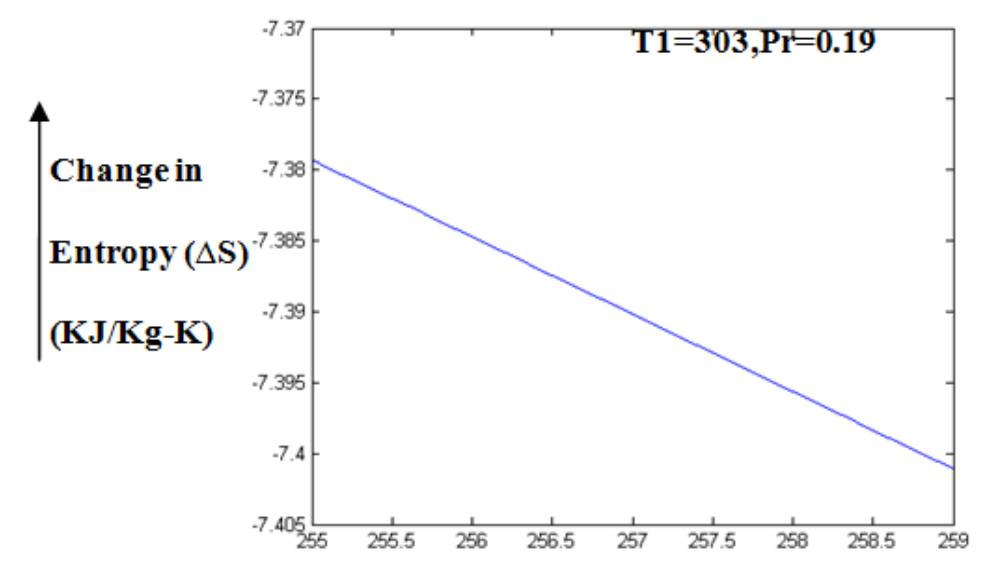

Outlet Temperature (T2) (K)

Fig. -2 shows the variation of change in entropy $(\Delta S)$ with the change of Outlet temperature (T2). Outlet temperature is made to vary from $255 \mathrm{~K}$ to $259 \mathrm{~K}$ and inlet temperature (T1) \& Pressure ratio $(\mathrm{Pr})$ are kept constant at $303 \mathrm{~K} \& 0.19$ respectively. From the figure it is clear that change in entropy is decreasing with the increase of outlet temperature. It has been found that change in entropy is minimu $\mathrm{m}$ at $259 \mathrm{~K}$.

6.3 Effect of Pressure ratio (Pr) on Change in Entropy $(\Delta \mathbf{S})$ -

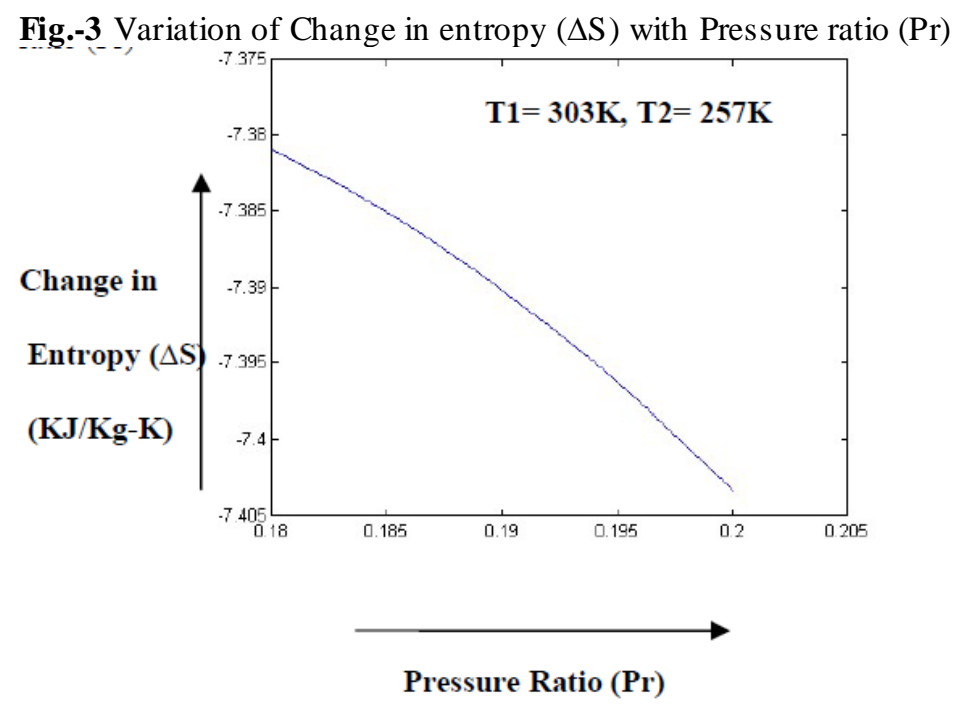

Fig.-3 shows the variation of change in entropy $(\Delta S)$ with the change of Pressure ratio $(\operatorname{Pr})$. Pressure ratio is made to vary from 0.18 to 0.20 and Inlet temperature (T1) \& Outlet temperature (T2) are kept constant at $257 \mathrm{~K} \& 303 \mathrm{~K}$ respectively. Fro $\mathrm{m}$ the figure it is clear that change in entropy is decreasing with increasing of Pressure ratio. It has been found from the graph that change of entropy is minimum when Pressure ratio is 0.20 .

\section{CONCLUSION}

In this study Taguchi methods of Design of Experiment (DOE) was used to examine how change in entropy $(\Delta S)$ in an expansion process of a cold storage vary with change of inlet 
temperature, outlet temperature \& pressure ratio. We know that from second law of thermodynamics, $\Delta \mathrm{S}=\Delta \mathrm{Q} / \mathrm{T}$ or $\mathrm{TdS}=\mathrm{dQ}$ and expansion process is an irreversible adiabatic process so in order to optimize the performance of expansion process we have to minimize the change in entropy. Following conclusion can be made from the analysis of results obtained from the mathematical model-

1. From the graphical analysis it is clear that the optimal conditions for an expansion process of a cold storage are inlet temperature $(\mathrm{T} 1)=$ $305 \mathrm{k}$, outlet temperature $(\mathrm{T} 1)=259 \mathrm{~K}$ and pressure ratio $(\mathrm{Pr})=0.20$. This optimum conditions of expansion are proposed in the range of- $\mathrm{T} 1=301 \mathrm{~K}-305 \mathrm{~K}, \mathrm{~T} 2=255 \mathrm{~K}-259 \mathrm{~K}$ $\& \operatorname{Pr}=0.18-0.20$.

2. When pressure ratio (Pr) is high then change of entropy $(\Delta S)$ is minimum.

3. For $\mathrm{T} 1=305 \mathrm{~K}, \mathrm{~T} 2=259 \mathrm{~K} \& \mathrm{Pr}=0.20$, the change in entropy is minimum.

\section{ACKNOWLEDGEMENT}

We would like to express our heartfelt gratitude to SRIRAM COLD STORAGE, Jalpaiguri, specially, Panditji for his valuable information and help. We would also like to thanks Prof. Asim Mahapatra, Department of Mechanical Engineering, JGEC, for his valuable advice \& help. We would also like to take this opportunity to extend our thanks to Prof. Dr. S.MUKHERJEE H.O.D., Department of Mechanical Engineering, and JGEC for his cooperation and insightful comments. Finally, we would like to thank our all the well wishers who helped us to make our work more organized and well-stacked till the end.

\section{REFERENCES}

[1] NASA, Glenn Research Center, Isentropic compression or expansion, https://www.grc.nasa.gov/www/k-

12/airplane/co mpe xp.html

https://www.grc.nasa.gov/www/k12/airplane/entropy.html.

[2] Principles of Vapor Compression Refrigeration System-written by: Harlan Bengtson - edited by: Lamar Stonecypher • updated: 2/8/2011; http://www.brighthubengineering.com/hvac/ 35435-principles-of-the-vapor-co mpres sionrefrigeration-system.

[3] Dr. N. Mukhopadhyay, Priyankar Mondal, "Optimization of Combined Conductive Heat Transfer Model of Cold Storage using Taguchi Analysis." Journal Of Engineering Research \& Applications,ISSN:2248-9622, Vol.5, Issue 11,(part 11), November 2015, pp.15-19, www.ijera.com
[4] "Superheat Stability of an Evaporator and Thermostatic Expansion Valve"- M. J. Lenger, A. M. Jacobi, and P. S. Hrojak, Air Conditioning and Refrigeration Center University of Illinois, Mechanical \& Industrial Engineering Dept.,1206 West Green Street, Urbana, IL 61801, ACRC TR138, July 1998.

[5] Dr. N. Mukhopadhyay, Suman Debnath, "Theoretical Convective Heat Transfer Model Development of Cold Storage Using Taguchi Analysis" Int. Journal of Engineering Research and Application, ISSN : 2248-9622, Vol. 5, Issue 1, ( Part -6) January 2015, pp.13-17 www.ijera.com.

[6] Engineering Thermodynamics by P K Nag, Fourth Edition, McGraw Hill Education India Pvt. Ltd., ISBN-13: 978-0-07-0260627, ISBN-10: 0-07-026062-1.

[7] Dr. Nimai Mukhopadhyay," Theoretical Study of Heat Load Calculation of a Cold Storage System" Proc. 6th.WMVC-2014, November 1-3, 201452 Siliguri (Darjeeling) pp.52-57.email:nm1231@gmail.com. 